11,13

\title{
Термодинамическая модель зародышеобразования кристаллов n-терфенила с анизотропией поверхностной энергии на межфазной границе жидкость-воздух
}

\author{
(C) В.А. Постников ${ }^{1}$, А.А. Кулишов ${ }^{1}$, А.А. Островская ${ }^{1,2}$, А.С. Степко ${ }^{3}$, П.В. Лебедев-Степанов ${ }^{3}$ \\ ${ }^{1}$ Институт кристаллографиии им. А.В. Шубникова ФНИЦ „Кристаллография и фоотоника“ РАН, \\ Москва, Россия \\ ${ }^{2}$ МИРЭА - Российский технологический университет (МИТХТ), \\ Москва, Россия \\ ${ }^{3}$ Центр фотохимии ФНИЦ „Кристаллография и фотоника“ РАН, \\ Москва, Россия \\ E-mail: postva@yandex.ru
}

Поступила в Редакцию 16 июля 2019 г.

В окончательной редакции 16 июля 2019 г.

Принята к публикации 25 июля 2019 г.

\begin{abstract}
Представлен анализ изменения свободной энергии Гиббса $\Delta G$ при образовании плоского зародыша кристалла $n$-терфенила на межфазной границе жидкость-воздух с учетом анизотропии поверхностной энергии граней. Значения поверхностной энергии граней кристалла $n$-терфенила были рассчитаны методом атомного силового поля OPLS, основываясь на структурных данных. Для анализа модели были привлечены экспериментальные сведения по росту кристаллов из растворов и их поверхностным свойствам.
\end{abstract}

Ключевые слова: зародышеобразование кристаллов, поверхностная энергия, поверхностное натяжение, межфазная граница жидкость-воздух, смачивание, свободная энергии Гиббса.

DOI: $10.21883 /$ FTT.2019.12.48572.45ks

\section{1. Введение}

Исследования по росту из растворов органических кристаллов выявили склонность у ряда веществ к образованию и росту на межфазной границе жидкостьвоздух тонких монокристаллических пленок и пластин [1-3]. Для кристаллизации на границе раздела жидкость-воздух метод ,растворитель-антирастворитель“ определен как наиболее эффективный в отношении стабильности эффекта, качества формирующихся кристаллов и скорости их роста [1-3]. В условиях данного метода осуществляется диффузия сольватофобного осадителя (антирастворителя) из паровой фазы в раствор, за счет чего максимум пересыщения имеет место на границе раздела фаз. Образование и флотация более плотных, чем раствор, кристаллов на поверхности жидкой фазы обеспечивается влиянием сил поверхностного натяжения, однако до сих пор нет ясного понимания механизма этого явления. Ранее в работах [2-3] был предложен термодинамический анализ образования плоских зародышей кристаллов в соответствующих условиях, однако анизотропия поверхностной энергии различных граней практически не была учтена. В данной работе на примере кристаллов $n$-терфенила проведен анализ изменения свободной энергии Гиббса с учетом анизотропии поверхностной энергии граней, значения которой были рассчитаны в приближении метода атомного силового поля. Также в данной работе проанализирован случай неполного смачивания раствором граней кристалла, по всей видимости, имеющий место в условиях метода „растворитель-антирастворитель“ из-за наличия сольватофобного осадителя.

\section{2. Экспериментальная часть}

\section{1. Рост кристаллов}

Исследования по росту и структуре кристаллов $n$-терфенила ранее нами представлены в работе [3]. В качестве растворителя использовали толуол (ОСЧ), а в качестве осадителя - этанол, изопропанол и бутанол-1 (ЧДА).

\section{2. Поверхностные свойства растворов и кристалла}

Исследования поверхностного натяжения растворов и краевого угла смачивания проведены на оптическом приборе ОСА $15 \mathrm{EC}$ при $22-24^{\circ} \mathrm{C}$. Поверхностное натяжение насыщенного раствора $n$-терфенила в толуоле определяли по методу висячей капли. Во избежание испарения капля раствора выдавливалась внутрь небольшой герметичной кварцевой кюветы с прозрачными стенками. Поверхностное натяжение капли насыщенного раствора было также определено в условиях атмосферы насыщенной парами изопропилового спирта, который предварительно наливали на дно кварцевой кюветы. Определение поверхностной энергии $\sigma_{001}^{V}$ было проведено на ряде кристаллов только для наиболее развитой грани (001) с помощью модифицированного 
уравнения Юнга, используя экспериментально измеренные значения краевого угла смачивания $\theta_{001}$ дистиллированной водой [4]: $\cos \theta_{001}=-1+2\left(\sigma_{001}^{V} \cdot \sigma_{W}^{d}\right)^{1 / 2} / \sigma_{W}$, где $\sigma_{W}=72.8 \mathrm{~mJ} / \mathrm{m}^{2}$ и $\sigma_{W}^{d}=21.8 \mathrm{~mJ} / \mathrm{m}^{2}[5]$ — поверхностное натяжение воды и вклад дисперсионных сил в данную величину соответственно.

\section{3. Методика расчета поверхностной энергии кристалла}

Поверхностная энергия граней кристалла $n$-терфенила была рассчитана методом атомного силового поля OPLS. Данный тип силового поля был разработан для расчета взаимодействия молекул и молекулярных кластеров, как для твердого тела [6], так и для жидкости [7] методами молекулярной динамики. В расчетах были использованы рентгеноструктурные данные [3] о взаимном расположении молекул в кристалле, а также - о положении атомов в молекуле, на основе чего были построены параллельные молекулярные бислои, лежащие в одной из трех кристаллографических плоскостей (001), (010) или (100), содержащие по нескольку десятков молекул. Определялась полная ван-дер-ваальсова энергия ориентированного бислоя $U_{h k l}$. Далее аналогично вычислялась энергия идентичных монослоев, составляющих бислой, $U_{1 h k l}$. Энергия связи бислоев равна $\Delta U_{h k l}=U_{h k l}-2 U_{1 h k l}$. В модели принято, что положительно определенная энергия когезии равна - $\Delta U_{h k l}$, а поверхностная энергия равна отношению энергии когезии к удвоенной площади монослоя: $\sigma_{h k l}=-\Delta U_{h k l} /\left(2 \cdot S_{1 h k l}\right)$.

\section{4. Результаты}

В таблице представлены расчетные значения поверхностных свойств и имеющиеся соответствующие литературные сведения, полученные методом функционала плотности [8]. Определенные нами значения поверхностной энергии граней, как видно из таблицы, оказались значительно ниже литературных. Также приведены экспериментальные сведения по поверхностному натяжению $\sigma_{L V}$ насыщенного раствора толуола и величине $\sigma_{001}^{V}$

Поверхностные свойства растворов толуола и кристалла $n$-терфенила

\begin{tabular}{c|c|c|c|c|c|c|c}
\hline \multirow{2}{*}{$\begin{array}{c}\sigma_{L V}^{1}, \\
\mathrm{~mJ} / \mathrm{m}^{2}\end{array}$} & $\begin{array}{c}\sigma_{L V}^{2}, \\
\mathrm{~mJ} / \mathrm{m}^{2}\end{array}$ & \multicolumn{2}{|c|}{$\begin{array}{c}\sigma_{100}^{V}, \\
\mathrm{~mJ} / \mathrm{m}^{2}\end{array}$} & \multicolumn{2}{c|}{$\begin{array}{c}\sigma_{010}^{V}, \\
\mathrm{~mJ} / \mathrm{m}^{2}\end{array}$} & \multicolumn{2}{|c}{$\begin{array}{c}\sigma_{001}^{V}, \\
\mathrm{~mJ} / \mathrm{m}^{2}\end{array}$} \\
\cline { 3 - 8 } & & расч. & эксп. & расч. & эксп. & расч. & эксп. \\
\hline $26.2 \pm 0.4$ & $25.7 \pm 0.2$ & $75 / 120$ & - & $86 / 136$ & - & $72 / 99$ & $50 \pm 8$
\end{tabular}

Пр и мечание. $\sigma_{L V}^{1}$ и $\sigma_{L V}^{2}-$ поверхностное натяжение насыщенного раствора толуола в воздухе и в атмосфере, насыщенной парами изопропанола соответственно; $\sigma_{100}^{V}, \sigma_{010}^{V}$ и $\sigma_{001}^{V}-$ значения поверхностной энергии различных граней кристалла, рассчитанные методом OPLS (расч.) и определенные экспериментальным способом (эксп.). Курсивом выделены литературные расчетные значения [8].

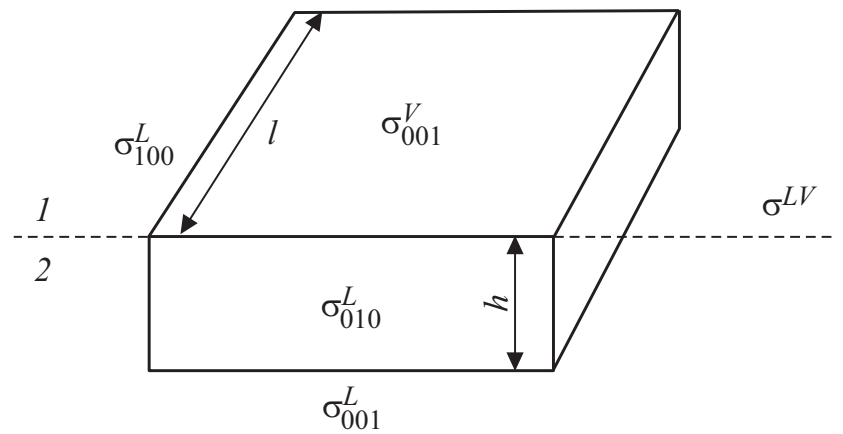

Рис. 1. Модель плоского зародыша кристалла на границе раздела жидкость (1)-воздух (2).

для плоской грани кристалла. В ходе экспериментов установлено, что на поверхности кристаллов $n$-терфенила капля насыщенного раствора толуола практически полностью растекается $\left(\theta_{001} \approx 0\right)$. Как видно из таблицы, экспериментальное значение поверхностной энергии $\sigma_{001}^{V}$ для реального кристалла оказалось заметно ниже, чем рассчитанное для идеальной кристаллической структуры.

\section{5. Термодинамическая модель образования плоского зародыша кристалла}

Рассмотрим модель плоского зародыша кристалла толщиною $h$, балансирующего на границе раздела фаз так, что верхняя грань (001) не контактирует, а боковые и нижняя грани находятся в контакте с раствором (рис. 1). Для упрощения рассмотрим зародыш прямоугольной формой со стороной $l$ и $c$ боковыми гранями (100) и (010). Тогда изменение свободной энергии Гиббса зародыша запишем в виде

$$
\begin{aligned}
\Delta G= & \Delta G_{V}+\Delta G_{S}=-\left(l^{2} h / \Omega\right) \cdot \Delta \mu+\left(\sigma_{001}^{V}\right. \\
& \left.+\sigma_{001}^{L}-\sigma_{L V}\right) l^{2}+2\left(\sigma_{100}^{L}+\sigma_{010}^{L}\right) \cdot l h,
\end{aligned}
$$

где первое слагаемое в правой части - объемная составляющая $\Delta G V \quad(\Omega=M / \rho-$ молярный объем, $M=0.2303 \mathrm{~kg} / \mathrm{mol}$ - молярная масса, $\rho=1241 \mathrm{~kg} / \mathrm{m}^{3}$ - плотность кристаллов при $298 \mathrm{~K}$ [3], $\Delta \mu=R T \cdot \ln \left(C / C^{*}\right)=R T \cdot \ln (1+\xi)$ - движущая сила кристаллизации, $\xi=\left(C-C^{*}\right) / C^{*}-$ относительное пересыщение раствора на границе фаз), а второе и третье - поверхностная составляющая $\Delta G_{S}$, которая определяется поверхностными энергиями граней на межфазных границах кристалл - воздух $\left(\sigma_{001}^{V}\right)$ и кристалл раствор $\left(\sigma_{001}^{L}, \sigma_{010}^{L}, \sigma_{010}^{L}\right)$, а также поверхностным натяжением раствора $\sigma_{L V}$ (рис. 1$)$. Из условия равновесия формы кристалла $\left(\Delta G_{S}=\min , l^{2} h=\mathrm{const}\right)$ следует соотношение между длиной и толщиной зародыша кристалла:

$$
h / l=\left(\sigma_{001}^{V}+\sigma_{001}^{L}-\sigma_{L V}\right) /\left(\sigma_{100}^{L}+\sigma_{010}^{L}\right) .
$$



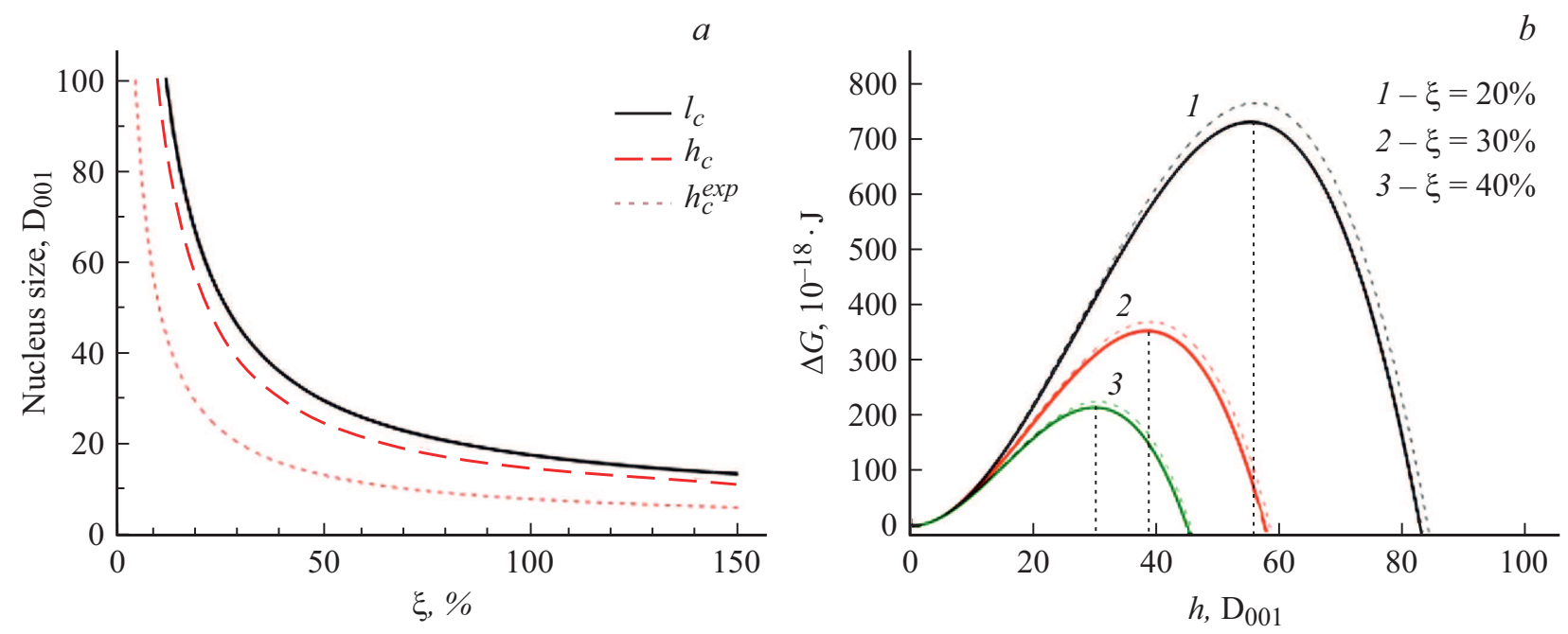

Рис. 2. $a$ - зависимость критических размеров зародыша от относительного пересыщения $\xi$ при $298 \mathrm{~K}\left(D_{001}=1.36 \mathrm{~nm}\right)$; $b$ - зависимость функции $\Delta G$ от толщины зародыша при различных значениях относительного пересыщения в случае полного (сплошные кривые) и не полного смачивания (пунктирные кривые) при $\theta=10^{\circ}$.

С учетом выражения (2), минимизация функции $\Delta G$ дает

$$
\begin{gathered}
l_{c}=(2 \Omega / \Delta \mu)\left(\sigma_{100}^{L}+\sigma_{010}^{L}\right), \\
h_{c}=(2 \Omega / \Delta \mu)\left(\sigma_{001}^{V}+\sigma_{001}^{L}-\sigma_{L V}\right) .
\end{gathered}
$$

Используя уравнение Юнга, можно установить взаимосвязь между поверхностной энергией грани (001) смоченной раствором $\sigma_{001}^{L}$ и сухой $\sigma_{001}^{V}$ :

$$
\sigma_{001}^{L}=\sigma_{001}^{V}-\sigma_{L V} \cdot \cos \theta_{001}
$$

где $\theta_{001}$ - краевой угол смачивания раствором поверхности грани (001) кристалла. Тогда для $l_{c}$ и $h_{c}$ можно записать следующие выражения:

$$
\begin{gathered}
l_{c}=(2 \Omega / \Delta \mu)\left(\sigma_{100}^{V}+\sigma_{010}^{V}-\sigma_{L V} \cdot\left(\cos \theta_{010}+\cos \theta_{100}\right)\right), \\
h_{c}=(2 \Omega / \Delta \mu)\left(2 \sigma_{001}^{V}-\sigma_{L V} \cdot\left(1+\cos \theta_{001}\right)\right) .
\end{gathered}
$$

Как видно из уравнений (5), длина критического зародыша $l_{c}$ определяется поверхностной энергией боковых граней, а толщина $h_{c}$ поверхностной с энергией наиболее развитой грани (001). В случае полного смачивания нижней и боковых граней кристалла раствором $(\theta=0)$ величины $l_{c}$ и $h_{c}$ будут минимальны, а при добавлении сольватофобного растворителя в систему (изопропанол) смачивание будет уже не полным и значения критических размеров зародыша возрастут.

На рис. 2, a приведены построенные по уравнениям (6) зависимости критических размеров $l_{c}$ и $h_{c}$ (в единицах толщины мономолекулярного слоя $D_{001}=1.36 \mathrm{~nm}$ ) зародыша кристалла $n$-терфенила от относительного пересыщения $\xi$ раствора толуола в условиях полного смачивания нижней и боковых граней при $298 \mathrm{~K}$. Нижняя пунктирная кривая на рис. 2, $a$ соответствует толщине критического зародыша $h_{c}^{e x p}(\xi)$ для найденного экспериментальным способом значения $\sigma_{001}^{V}$.
Как видно из рисунка, значение $h_{c}^{e x p}(\xi)$ почти вдвое ниже величины $h_{c}$, определенной на основе теоретической оценки поверхностной энергии. На рис. $2, b$ представлен построенный по уравнению (1) график зависимости функции $\Delta G$ от толщины зародыша $h$ для разных значений $\xi$. Для расчета были использованы установленные нами теоретические значения поверхностной энергии граней кристалла. Как видно из рисунка, параметры критического зародыша, размер и высота энергетического барьера, определяемые максимумом функции $\Delta G$, существенно снижаются с ростом пересыщения. В условиях метода „растворителя - антирастворителя“ имеет место не полное смачивание раствором поверхности кристалла. На рис. $2, b$ в виде пунктирных линий представлены зависимости $\Delta G(h)$ при соответствующих пересыщениях для значения $\theta_{001}=\theta_{010}=\theta_{100}=10^{\circ}$. Как видно из рисунка, в данном случае энергетический барьер образования зародыша выше на $4-5 \%$, чем в условиях полного смачивания.

\section{6. Заключение}

В рассмотренной модели через использование уравнения Юнга для параметров зародышеобразования на границе раздела жидкость-воздух учтена зависимость от краевого угла смачивания граней кристалла. В условиях роста по методу „растворитель-антирастворитель“, когда имеет место рост контактного угла смачивания по мере увеличения концентрации осадителя (изопропанол), критические размеры и энергетический барьер образования зародыша будут расти, а скорость зародышеобразование снижаться, что, возможно, объясняет более высокое качество формирующихся в данных условиях монокристаллических пленок. 


\section{Финансирование работы}

Работа выполнена при поддержке Министерства науки и высшего образования в рамках выполнения работ по Государственному заданию ФНИЦ „Кристаллография и фотоника“ РАН с использованием оборудования ЦКП ФНИЦ „Кристаллография и фотоника“ при поддержке Минобрнауки (проект RFMEF162119X0035)

\section{Конфликт интересов}

Авторы заявляют, что у них нет конфликта интересов.

\section{Список литературы}

[1] V.A. Postnikov, Y. Odarchenko, A.V. Iovlev, V.V. Bruevich, A.Y. Pereverzev, L.G. Kudryashova, V.V. Sobornov, L. Vidal, D. Chernyshov, Y.N. Luponosov, O.V. Borshchev, N.M. Surin, S.A. Ponomarenko, D.A. Ivanov, D.Y. Paraschuk. Cryst. Growth Des. 14, 1726 (2014).

[2] В.А. Постников, С.В. Чертопалов. Кристаллография 60, 651 (2015).

[3] В.А. Постников, Н.И. Сорокина, О.А. Алексеева, А.А. Кулишов, Р.И. Сокольников, М.С. Лясникова, В.В. Гребенев, О.В. Борщев, М.С. Скоротецкий, Н.М. Сурин, Е.А. Свидченко, С.А. Пономаренко, А.Э. Волошин. Кристаллография 63, 801 (2018).

[4] Е.Д. Щукин, А.В. Перцов, Е.А. Амелина. Коллоидная химия. Высш. шк., М. (2004). 445 с.

[5] М. Джейкок, Д. Парфит. Химия поверхностей раздела фаз. Мир, М. (1984). 269 с.

[6] W.L. Jorgensen, J. Tirado-Rives. J. Am. Chem. Soc. 110, 1657 (1988).

[7] W.L. Jorgensen, D.S. Maxwell, J. Tirado-Rives. J. Am. Chem. Soc. 118, 11225 (1996).

[8] P. Puschnig, D. Nabokand, C. Ambrosch-Draxl. Interface Controlled Organic Thin Films. Springer Proceedings in Physics 129 / Ed. H.-G. Rubahn, H. Sitter, K. Al-Shamery. Springer (2009). P. 3.

Редактор Т.Н. Василевская 